\title{
From Affirmative Action to Inclusion
}

\author{
Linda F. Bisson, Laura Grindstaff, Kyaw Tha Paw U, Raquel E. Aldana, \\ Sophie J. Barbu, Lisceth Brazil-Cruz, Adela De La Torre, \\ Mary Lou de Leon Siantz, Yvette G. Flores, Denneal Jamison-McClung, \\ Suad Joseph, Philip H. Kass, Linda Katehi, Karen McDonald, \\ Josephine M. Moreno, Binnie Singh, Maureen Stanton, and Lisa Sullivan
}

\begin{abstract}
Achieving a diverse and inclusive community requires establishing a culture of genuine equality for all members. Our purpose in writing this book is to share our collective knowledge about how to challenge the forces that enable and sustain discrimination in the workplace as informed by our experience developing and implementing the UC Davis ADVANCE program. The program's goal is to create an inclusive academic community that reflects and serves the diverse population of California. In this introductory chapter, we emphasize the need to move
\end{abstract}

\section{F. Bisson (ه)}

Department of Viticulture and Enology, University of California, Davis, Davis, CA 95616, USA e-mail: 1fbisson@ucdavis.edu

L. Grindstaff

Department of Sociology, University of California, Davis, Davis, CA 95616, USA

e-mail: lagrindstaff@ucdavis.edu

K. T. Paw U

Department of Land, Air and Water Resources, University of California, Davis, Davis, CA 95616, USA

e-mail: ktpawu@ucdavis.edu

R. E. Aldana

School of Law, University of California, Davis, Davis, CA 95616, USA

e-mail: realdana@ucdavis.edu

S. J. Barbu

UCD NSF Davis ADVANCE Program, University of California, Davis, Davis, CA 95616, USA

e-mail: sjbarbu@ucdavis.edu

L. Brazil-Cruz

UC Davis ADVANCE Program, University of California, Davis, Davis, CA 95616, USA

Institutional Effectiveness, Woodland Community College, 2300 E. Gibson Road, Woodland, CA 95776, USA

L. Brazil-Cruz

e-mail: lizcruz@ucdavis.edu; lbrazil@yccd.edu

A. De La Torre

Office of the President, California State University - San Diego, 5500 Campanile Dr, San Diego, CA 92182, USA

e-mail: aidelatorre@sdsu.edu

L. F. Bisson et al. (eds.), Uprooting Bias in the Academy, https://doi.org/10.1007/978-3-030-85668-7_1 
from affirmative action programs, which have played an important role in fostering diversity, to a focus on institutional transformation, which requires not only changes in policy but also shifts in academic culture. Much of what we cover in this book is broadly applicable beyond academia and will interest those wanting to understand and address challenges to diversity, equity, and inclusion in their own organizations. Since workplaces differ in their goals, priorities, and culture, the book is not a "how to" manual but rather a collective effort to share with readers the approaches we took, the information we gathered, what we observed and experienced, and the lessons we learned along the way.

Keywords Affirmative action · Inclusion • NSF ADVANCE • Proposition 209

M. L. de Leon Siantz

Betty Irene Moore School of Nursing, UC Davis Health System, University of California, Davis, 2315 Stockton Blvd., Sacramento, CA 95817, USA

e-mail: deleonsiantz@ucdavis.edu

\section{Y. G. Flores}

Department of Chicana/o Studies, University of California, Davis, Davis, CA 95616, USA

e-mail:ygfloresortiz@ucdavis.edu

D. Jamison-McClung

UC Davis Biotechnology Program, University of California, Davis, Davis, CA 95616, USA

e-mail: dsjamison@ucdavis.edu

\section{S. Joseph}

Department of Anthropology, University of California, Davis, Davis, CA 95616, USA

e-mail: sjoseph@ucdavis.edu

P. H. Kass

School of Veterinary Medicine, University of California, Davis, Davis, CA 95616, USA

e-mail:phkass@ucdavis.edu

L. Katehi

Department of Electrical and Computer Engineering, University of California, Davis, Davis, CA 95616, USA

e-mail:katehi@ucdavis.edu

K. McDonald

Department of Chemical Engineering, University of California, Davis, Davis, CA 95616, USA

e-mail: kamcdonald@ucdavis.edu

J. M. Moreno

Graduate Studies, University of California, Davis, Davis, CA 95616, USA

e-mail:mjmoreno@ucdavis.edu

B. Singh

University of California, Davis, Davis, CA 95616, USA

e-mail: binsingh@ucdavis.edu 


\title{
1 Introduction
}

The National Science Foundation ADVANCE Institutional Transformation (NSF ADVANCE-IT) program is a federally-funded initiative focused on increasing the participation of women in academia across science, technology, engineering, and mathematics (STEM) fields. In the U.S., the percentage of female faculty, and especially of female faculty of color, continues to lag behind the pool of women obtaining graduate degrees in these fields. The NSF ADVANCE-IT program provides funding to institutions to address this inequality and to define the factors inhibiting diversity along the STEM career path.

The University of California-Davis received an ADVANCE-IT grant in 2012 in order to create an ADVANCE program on our campus. As program leaders, we have focused our efforts on understanding the intersection of gender and race as it pertains to the marginalization of women in STEM. Given the demographics of California and the public mission of the campus to serve the diverse peoples of the state, we focus particularly on the marginalization of Latina STEM scholars. Other ADVANCE awardee institutions have sought to develop affirmative action programs to address inequalities in faculty hiring and advancement. California Proposition 209, a voter-approved constitutional change that prohibits state governmental institutions from considering race or gender in employment or education decisions (and thus bans many affirmative action programs), led us to take a different approach.

We recognize both the value and the limitations of affirmative action initiatives and understand the difference between being diverse and being inclusive, a distinction that affirmative action programs (along with many of the diversity initiatives that replaced them) do not always address. Being diverse refers to the fact that individuals belonging to a wide variety of social identity categories are present in a given setting. Being inclusive refers to the fact that people with different social identities both feel and actually are valued in that setting. In developing our own ADVANCE program at UC Davis, our overarching goals have been to identify barriers to inclusion and to understand why many women, especially women of color, remain underrepresented in STEM careers. In this and subsequent chapters, we share the knowledge we have gained, along with our assessments of programs and practices developed to enhance inclusion. We hope this book will help inform and inspire those interested in fostering a diverse, inclusive work environment.

\author{
M. Stanton \\ Department of Evolution and Ecology, University of California, Davis, Davis, CA 95616, USA \\ e-mail: mlstanton@ucdavis.edu \\ L. Sullivan \\ School of Education, University of California, Davis, Davis, CA 95616, USA \\ e-mail: lhsullivan@ucdavis.edu
}




\section{The Mandate and Legacy of California Proposition 209}

Although diversity, equity, and inclusion (DEI) initiatives have largely replaced affirmative action programs in both the corporate world and higher education today, their roots are entangled. Kelly and Dobbin (1998) argue that affirmative action effectively became "diversity management" as the former faced increasing legal and political backlash initially in the 1980s (under President Reagan) and continuing through the 1990s (under President Clinton). Affirmative action first arose in response to federal efforts to outlaw employment discrimination during the Civil Rights era, notably President Kennedy's Executive Order 10,925 in 1961 and Title VII of the Civil Rights Act in 1964. Employers sought to comply, hiring specialists to create programs to shield them from litigation (Kelly \& Dobbin, 1998; see also Edelman, 1992). As legal and political challenges to affirmative action gained traction in subsequent decades, certain offices and activities survived by inventing the discipline of "diversity management," which recast workplace integration goals in terms of efficiency, organizational effectiveness, and business success. Unsurprisingly, as Kelly and Dobbin (1998) note, the employment practices and programs that survived the attack on anti-discrimination/affirmative action law were least effective at changing the gender and racial composition of the workplace.

California, while following this overall pattern of retrenchment, has a particular history with regard to affirmative action that has shaped how the UC system can remedy systemic race- and gender-based discrimination in the hiring, promotion, and retention of faculty. In 1996, a narrow majority (55\%) of California voters passed Proposition 209, which outlawed public-sector affirmative action policies in the state. Titled "Prohibition Against Discrimination or Preferential Treatment By State and Other Public Entities," the Proposition added to the California State constitution language banning discrimination in all state agencies, with "discrimination" understood to apply to white men as well as historically underrepresented groups. In November of 2020, voters had the opportunity to repeal Proposition 209 and a slightly broader majority (57\%) voted against repeal - thus reaffirming this added language in the constitution and effectively continuing the ban on affirmative action as an approach to increasing workplace (and classroom) diversity. The pertinent sentence of Proposition 209 reads: "The state shall not discriminate against, or grant preferential treatment to, any individual or group on the basis of race, sex, color, ethnicity or national origin in the operation of public employment, public education, or public contracting" (California Ballot Pamphlet General Election: Proposition 209 Prohibition Against Discrimination or Preferential Treatment by State and Other Public Entities, 1996).

Proposition 209 was originally put on the ballot following the successful bid by two influential University of California Regents-Ward Connerly and then Governor Pete Wilson-to prevent the University of California from continuing to use many affirmative action initiatives. A year earlier, in July 1995, the UC Regents passed special orders SP1 and SP2, which ended any UC programs deemed to give "preferential treatment" to groups such as underrepresented minorities. Then Governor 
Pete Wilson was embarking on a presidential candidacy run, and some viewed SP1 and SP2 as a political maneuver to advance his career aspirations and to build the necessary momentum to introduce and pass Proposition 209 (Douglass, 1997). That Ward Connerly, a black man, supported Prop 209 lent credence to this effort.

Proposition 209 mandated the end of programs defined as "preferential treatment," including all quota systems as well as all affirmative action measures aimed at addressing historically persistent race- and gender-based discrimination. The language of the proposition re-cast these race- and gender-based affirmative action programs as perpetuating discrimination, not eliminating it. The "victims" of this ostensible discrimination were said to be white men being passed over in favor of "less qualified" workers, and also, ironically, white women and under-represented minority men of color themselves - the very constituencies affirmative action was designed to help. The latter groups supposedly suffered under affirmative action because the granting of "special preferences" implied an inability to advance on the basis of individual merit. This argument was made clear in the ballot pamphlet, as presented in Fig. 1.

The constitutionality of Proposition 209 was soon challenged. Federal courts subsequently upheld the measure (122 F.3d 692, 1997). The U.S. 9th District Court, in reaching its decision supporting the proposition's constitutionality, cited the language against discrimination as being consistent with the 14th Amendment to the U.S. Constitution. In expressing support for the court's ruling in a Washington Post story, California Governor Pete Wilson called it a "victory for every Californian [and] for every man, woman and child who asks only that he or she be treated equally and fairly under the law on the basis of merit" (Claiborne, 1997) University of California regent Connerly discussed his view of those who opposed Proposition 209 in a Los Angeles Times editorial: "I hope they realize the damage they are doing to our society

\footnotetext{
"Let's not perpetuate the myth that "minorities" and women cannot compete without special preferences. Let's instead move forward by returning to the fundamentals of our democracy: individual achievement, equal opportunity and zero tolerance for discrimination against--or for--any individual." (emphasis theirs)
}

http://vigarchive.sos.ca.gov/1996/general/pamphlet/209text.htm

Fig. 1 Text from the proposition 209 ballot pamphlet 
by trying to frustrate the will of the majority of Americans, who want to achieve a society of genuine equality for all and special privileges for none" (Connerly, 1997).

Although SP1 and SP2 were rescinded in 2001, Proposition 209 has remained state law for the past 25 years. As noted, voters in November 2020 opted not to repeal it, despite the fact that all ten UC Regents went on record in support of restoring affirmative action in the state. ${ }^{1}$ The willingness of politicians, educators, and other state leaders to positively re-evaluate the value and efficacy of affirmationaction-style initiatives is in no small way a response to the persistence of stark racial inequalities in California and U.S. society more broadly - a reality underscored most recently by the COVID-19 pandemic and public protest against anti-black police violence. Assuming we can all compete equally on the basis of merit presumes a race-neutral (i.e., race-equitable) context which doesn't exist, and never has. Indeed, not acting affirmatively to counter racism (and other forms of social inequality) in the pursuit of equity is itself racist, just as positively "discriminating" by implementing race-conscious policies is anti-racist if it helps create equity (see Kendi, 2019).

A research report authored by UC faculty reveals the negative consequences of Proposition 209 for women in the UC system, as the number of women faculty hired into the University of California, including UC Davis, dropped dramatically (the report does not distinguish between white women and women of color, but given other institutional data we can assume a white majority). Before 1995, the UC was hiring women at an increasing rate, suggesting a certain level of support for affirmative action goals. Between 1984 and 1995, the percentage of new female hires system-wide rose from approximately $25-35 \%$, while for UC Davis that percentage rose from approximately $25 \%$ to slightly over $50 \%$ (West et al. 2005). Following the passage of SP1, SP2, and Proposition 209, the percentage dropped to mid-1980s levels. There was a $21 \%$ drop in hires at UC Davis, representing about a $50 \%$ relative drop in the hiring rate of women; for the systemwide data, the drop was about $9 \%$, representing a $26 \%$ relative drop in the hiring rate of women. ${ }^{2}$ West et al. (2005) posit the changes reflected a return to explicit and implicit bias against women, which were decreasing under the stronger affirmative action years prior to 1995 . The lesson here is that gradual progress in combatting institutional bias can be erased relatively quickly by political events: in one to two years, the gains from the previous decades were undone.

None of this is to argue that affirmative action programs and policies are problemfree or even the most effective way to uproot historical discrimination. Indeed, the very need for such programs is itself proof that societal-level disadvantage remains intact. Many affirmative action programs throughout the U.S. have helped institutions diversify and promote individual achievement, but whether under the rubric of "affirmative action" or "diversity," a "fix the numbers" approach does not guarantee

\footnotetext{
${ }^{1}$ https://www.universityofcalifornia.edu/press-room/uc-board-regents-endorses-aca-5-repeal-pro p-209.

${ }^{2}$ To arrive at these numbers, we applied standard linear regression to the data between 1984 and 1995, and for the data between 1996 and 2002, then compared the predicted values for the year 1995, to estimate the percentage drop in females hires associated with SP1, SP2, and Proposition 209.
} 
an inclusive environment. Nor does it address the flip side of historical disadvantage: historical privilege (sometimes referred to as "legacy privilege"), by which we mean the advantages that accrue from membership in dominant (highly valued) social categories-being white, male, upper-class, able-bodied, cisgender, heterosexual, etc. The continued existence of race and gender bias against white women and people of color and in favor of white men, despite having affirmative action in place, is well-documented in the literature (see Stewart \& Valian, 2018) and underscores the importance of factors other than numerical representation in addressing social inequality in the workplace.

In the decades since Proposition 209 was passed, the University of California has developed institutional methods for diversifying UC campuses in accordance with the law, as exemplified in the Sept. 2016 publication, "Guidelines for Enhancing Diversity at UC in the Context of Proposition 209." The gradual success of postProposition 209 programs and efforts to shift academic culture are reflected in the increasing percentage of new hires that are female, with rates approximating the pre-Proposition 209 rise (see Fig. 2).

That the rate of increase is similar before and after the passage of Proposition 209 implies that the diversity enhancement programs following Proposition 209 have been roughly as effective as the affirmative action programs preceding it. We proceed from this basis, acknowledging the historic importance of affirmation action in disrupting persist patterns of marginalization on the basis of race and gender, while at the same time seeking to address the missing dimensions of equity and inclusion and their impact on faculty culture.

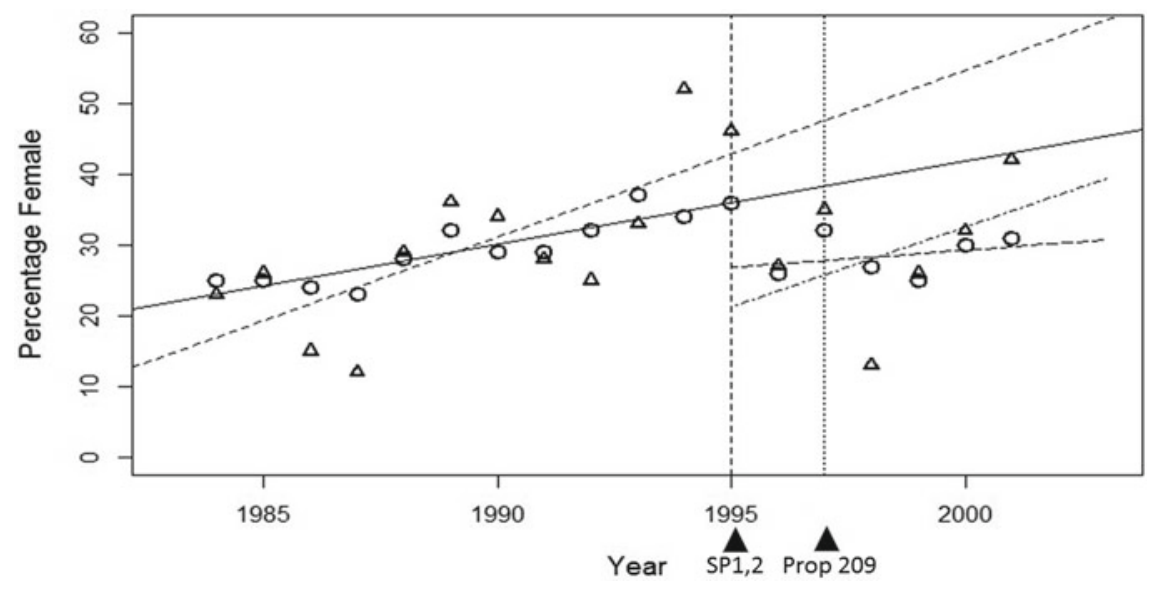

Fig. 2 Drop in percentage of women in new faculty hires following the passage of SP1, SP2 and proposition 209. University of California system (UCS, circles), and the University of California, Davis (UCD, triangles). Regression lines for pre-SP1\&SP2, and for post-SP1\&SP2, for UCD and UCS are shown. Based on data from UC Academic Senate (2003), after West et al. (2005) 


\section{Equality, Equity, and Inclusion}

Much social science literature discusses the origins and nature of discrimination in contemporary U.S. society, as we discuss in the chapter 'Barriers to Inclusion'. Here, three concepts are important to define: equality, equity, and inclusion. Figure 3 contrasts the nature and impacts of equal treatment with those of equity programs.

In this depiction, the fence represents a barrier that is clearly discriminatory. Some individuals have full access to the view behind the fence while others are blocked by the barrier. The boxes represent programs or processes that enable access. In the left panel, all individuals have the identical advantage of one identical box on which to stand. The individual on the far left, perhaps because of body height, has full access without need of a box. The panel on the right demonstrates equality of outcome (equity). In this case all individuals now have the same view (or access)-however, an unequal distribution of boxes is needed to achieve this. Achieving equity requires that the boxes be distributed disproportionately so as to address the disadvantages arising from the barrier. This analogy makes it clear that "being treated equally" is not the same as "being given equal opportunity." Tension between equality and equity arises because discriminatory barriers create inequality of access, and such barriers are widespread throughout society. Thus, to extend the analogy of the playing field shown in Fig. 3, the societal challenge is not so much the number and distribution of boxes but instead the fence itself. Figure 4 adds a panel to the right that depicts the outcome of genuine equality, where individuals of all types have equal access because the discriminatory nature of the barrier - the fence-has been eliminated.

When efforts to foster inclusion are successful, discriminatory barriers denying access or equality of treatment are eliminated. As inclusion is enhanced, the difference between "equal treatment for all" and "equal opportunity for all" disappears. Extending the analogy further, the boxes can be thought of as special privileges designed to counter historical disadvantage represented by the fence,
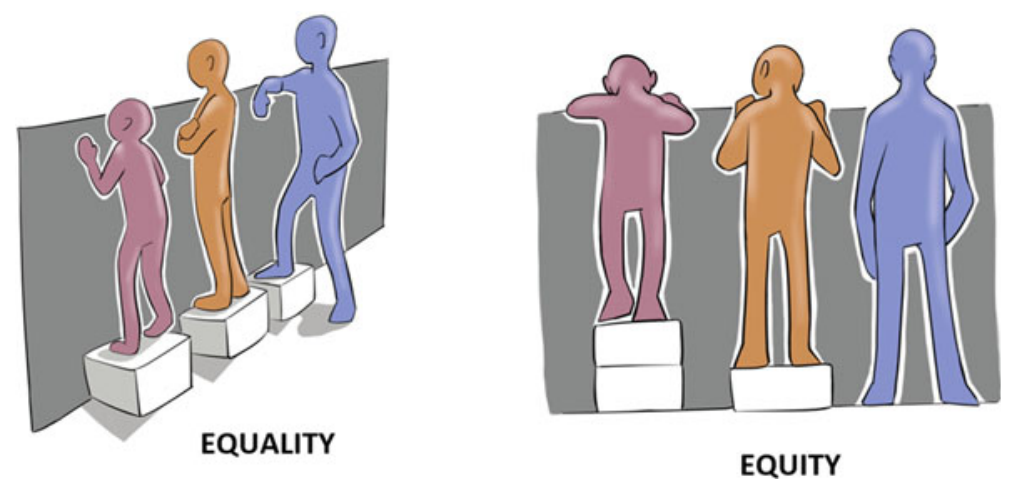

Fig. 3 Equality versus equity in access. Illustrations by Chastine Leora Madla 


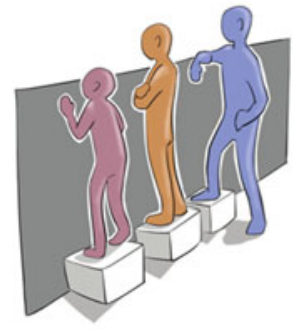

EQUALITY

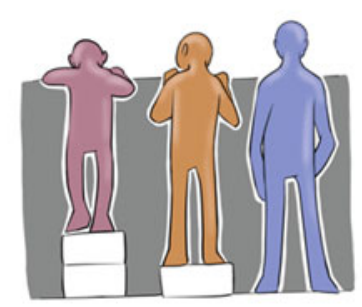

EQUITY

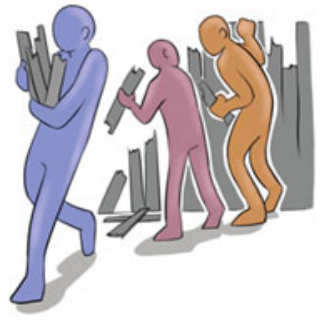

INCLUSION

Fig. 4 Equality and equity versus inclusion and the removal of barriers to access for all individuals. Illustrations by Chastine Leora Madla

but they are workarounds that do not address the broader impacts of historical disadvantage/privilege or create genuine equality.

We would like to note the difference between our use of "diversity" and "inclusion." Diversity is defined as participation by various groups in society (the more groups, the more diverse), as evidenced by their mere presence. Although diversity of participants may suggest inclusion, this is not always the case. Diversity is a necessary step on the road to inclusion, as illustrated in Fig. 5. The first panel depicts exclusion-where some groups are denied access. The second panel depicts segregation-the attempt to create a climate of "separate but equal" participation. The third panel depicts integration-bringing together previously segregated groups. Affirmative action programs have traditionally been aimed at achieving diversity, integration, and guaranteed access - in effect, "a seat at the table"-but many such programs failed to guarantee the quality of that access. Quality, in this case, means full incorporation into the activities of the group. Inclusion recognizes not only the rights of all members to participate but also the equivalent nature or quality of that participation. The final panel depicts the situation when inclusion exists-when the views and opinions of all participants are sought equally, valued equally, and respected fully.

\section{The UC Davis Advance Program}

The NSF ADVANCE award enabled UC Davis to assess issues of systemic bias, inequality, and equity in STEM fields. At the same time, we saw this as an opportunity to think more broadly about our campus culture than the narrow STEM focus of the grant. As members of the UC Davis ADVANCE program, our goal has been to create an inclusive campus climate consistent with Proposition 209. A critical yet partial metric of success is achieving and retaining numerical diversity within the ranks of STEM faculty. Accomplishing a broad vision of diversity and inclusion, however, requires understanding the nature of discrimination in contemporary U.S. society as 


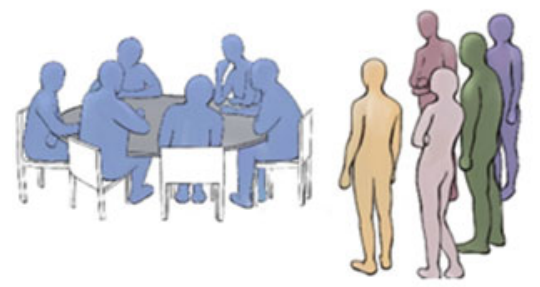

EXCLUSION

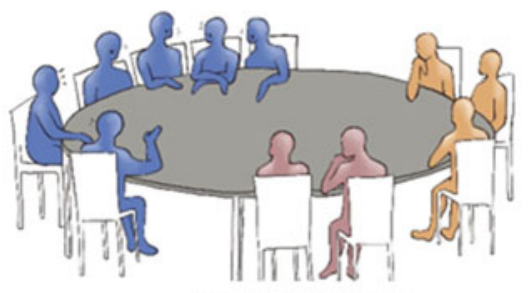

INTEGRATION

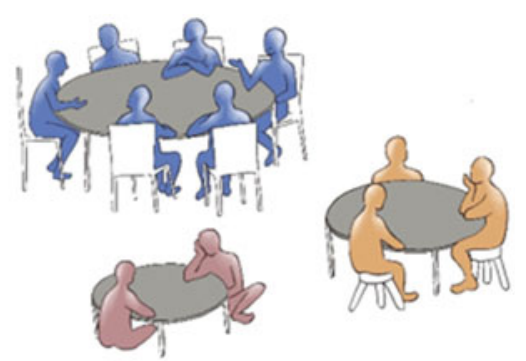

SEGREGATION

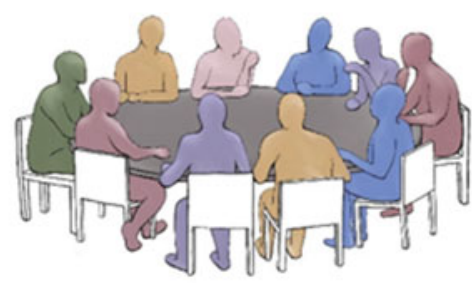

INCLUSION

Fig. 5 The path to inclusion. Segregation and integration illustrations by Mengmeng Luo and exclusion and inclusion illustrations by Meghan Crebbin-Coates

well as the ways in which historical privilege for some and disadvantage for others continues to create barriers to full equality.

NSF ADVANCE programs are tasked with transforming educational institutions by eliminating barriers that impede the ability of women and other underrepresented groups to achieve and thrive in academic STEM careers. At UC Davis, we will have reached our goal of working and living in a genuinely inclusive culture when such equity programs are no longer necessary or relevant. We seek outcomes that not only respect the rights of all members to participate but also achieve a deeper understanding and appreciation of the benefits to the group of multiple, diverse perspectives. In short, we seek to create a truly inclusive STEM and non-STEM environment.

\section{Creating a More Inclusive STEM Academic Environment}

Creating a more inclusive culture requires first understanding how the current environment sustains systemic bias, inequality, and inequity. To achieve this understanding, we undertook several initiatives. First, it was important to understand our own data on diversity at different levels of the academy. Numerical data provide 
insight into what is happening but not why it is happening. Surveys, interviews, focus groups and other tools can assist in defining reasons behind numerical trends. In addition to understanding data, it is important to fully assess institutional policies and practices to define areas where systemic bias, inequality, or inequity may arise, intentionally or unintentionally. Academic institutions are assumed to be meritocracies, meaning advancement is largely tied to continued accomplishment, assessed periodically via (seemingly objective) metrics. These assessments, however, can be susceptible to bias if the metrics employed assess factors that are not equally accessible. It is important to both understand the drivers of inequity in advancement and to implement programs that address them. Toward this end we launched mentoring, networking, and advising programs to help level the playing field for faculty.

We began our efforts knowing that the lack of racial and gender diversity in academia, as well as the existence of inhospitable climates for female and minority scholars, has multiple causes ranging from benign neglect to overt hostility, and from personal/individual behavior to institutional structures (National Academy of Sciences, National Academy of Engineering and Institute of Medicine, 2007; Stewart $\&$ Valian, 2018). Much discussed in the literature is the concept of bias, both unconscious and subconscious (implicit), which refers to a pervasive and cumulative cognitive process or set of schemas that can lead to discrimination by passive discouragement (Valian, 1998). Bias is at play, for example, when women of color are presumed to be less competent, reliable, or authoritative than their white male counterparts in a workplace. The pervasiveness of such bias makes the achievement of inclusive cultures a seemingly daunting task. Unconscious bias develops in childhood (Dhont \& van Hiel, 2012; Halim et al., 2017), and it is difficult to unlearn childhood experiences. Subtle forms of bias and discrimination against women and other groups in academia have been recognized for more than 50 years (Bernard, 1965; Rossi, 1965) and continue to thwart progress toward inclusion.

The members of the UC Davis ADVANCE leadership team were understandably influenced by both social science research and the experiences of other ADVANCE institutions as we set about to design our robust program. One issue that repeatedly arose in conversations with other ADVANCE leaders around the country was the transient nature of commitments made to inclusion — and the resulting backsliding when campus leadership and priorities changed. We concluded that transient transformation is not true transformation, rather it can reflect a top-down approach that is ineffective/unstainable because detached from the communities it seeks to change. Consequently, our ADVANCE Program has focused on creating a community-centered commitment to inclusion that prioritizes accountability. Leadership from the top does matter, but it must complement and amplify efforts on the ground while taking responsibility for outcomes.

Embracing a multi-pronged and multi-level approach to institutional transformation is supported the by existing literature outside the academy. Admittedly, research on the effectiveness of workplace diversity programs is inconclusive-in part because different programs prioritize different avenues of redress, some aiming to establish organizational responsibility for change, some tackling managerial bias through training, and some seeking to reduce the social isolation of women and 
minority workers through networking (see Kalev et al., 2006). In their analysis of federal management-level data from 708 private-sector companies, Kalev al. (2006) conclude that, of the three interventions, companies that prioritize organizational responsibility were most effective at increasing managerial diversity in terms of sheer numbers, and in this sense they mirrored more traditional affirmative action programs; at the same time, organizations that establish responsibility also see better effects from both diversity trainings and networking/mentoring efforts, which, ideally, go beyond numbers address non-inclusive cultures. Institutions that prioritize all three dimensions are therefore poised to effect deeper, more sustainable change. Whatever the avenue of redress, a commitment to diversity, equity, and inclusion should be rooted in the community in question-and reflect a deep understanding of that community. When this understanding is lacking, transformation efforts are more likely to fail (see Kotter, 1995).

\section{The Path to Inclusion}

This book is divided into five sections that detail how our UC Davis ADVANCE team approached the task of creating a more inclusive STEM community.

\section{Part 1}

The first section describes how we developed an understanding of the nature of discrimination within our organization. The chapter, 'Barriers to Inclusion,' discusses the social roots of discrimination and barriers to inclusion, including the role played by social processes in establishing/sustaining bias. Which barriers matter and how they operate varies, of course, by local culture and context. The chapter, 'Barriers to Inclusion,' along with this chapter make the case that we need change and that the foundation for change is understanding what drives systemic bias, inequality, and inequity.

\section{Part 2}

The second section describes our efforts to understand our own data and to review policies and practices for potential bias and inequity; it also outlines how our ADVANCE program was organized.

Undertaking a cultural transformation always requires buy-in from the affected communities. Buy-in requires a thorough understanding of the importance of inclusion and how/why the institution may be falling short. This the focus of the chapter, 'Data-Driven Decision Making,' which assesses local campus data on diversity, reports the results of surveys on local barriers to inclusion, and evaluates the effectiveness of existing equity programs - three steps that are vital in establishing baseline levels of bias and creating a path to equality. 
The chapter, 'Assessing Institutionalized Bias,' provides a guide for evaluating existing institutional policies and procedures to determine if they perpetuate discrimination. The aim of such evaluations is to understand how local culture can unknowingly institutionalize bias and non-inclusion. How policies are enacted and operationalized may introduce bias, making a review of practices every bit as important as a review of the actual policies. To achieve inclusivity, practices and policies must be internally consistent.

Chapter 'Leadership and Organizational Structure', the final chapter in this section, discusses the challenges of institutional transformation and its scope and the importance/role of consistent leadership in this process. Commitment from an organization's leadership is essential for a principled, action-oriented approach to inclusion. Addressing systemic bias and inequity is not simple; it requires a longterm commitment to change. Sustaining enthusiasm for change is a challenging but critical task for leaders because they are not only visible, they also set priorities and command resources.

\section{Part 3}

The third section of the book focuses on our main target demographic, Latina STEM scholars. The chapter, 'A Long-Term Vision on Faculty Diversity at UC Davis,' discusses the creation of a broad vision of faculty diversity and inclusion. The sustainability of ADVANCE beyond its early successes at UC Davis largely depends on whether it can propel the types of changes we know are critical to prioritize in the future. One type of transformational change is expanding the pipeline of Latinx and other underrepresented students into Ph.D. programs, both generally and in STEM specifically. We must enlarge the pool of underrepresented minority (URM) Ph.D. students both at UC Davis and nationally, as well as support successful careers after graduation, whether as professors in academia or research scientists in government or industry. At UC Davis, these efforts have already begun in earnest; they include visionary recruitment practices for graduate students, changes in graduate admissions practices, and improved mentoring of students both during and after completion of their programs.

The chapter, 'Making Visible the Invisible', focuses on the experience of conducting collaborative, interview-based research on the career pathways of a small sample of Latina STEM scholars across the United States. We address the process of conducting the research and explain why the Latina experience is crucial to understanding current discriminatory practices. In addition to discussing the theoretical foundations of our methodology and the importance of qualitative, in-depth interviews as a specific form of knowledge-production, we cover such topics as researcher ethics, how our identity influences perception and interpretation (positionality), issues of confidentiality and emotional labor, and the advantages and challenges of interdisciplinary collaboration. 


\section{Part 4}

Systemic bias creates inequity and inequality within an organization. Previous chapters discussed assessment of systemic bias and its impact in hiring and advancement for STEM faculty. In the fourth section we describe specific programs that we launched to increase equity and inclusion for all faculty on our campus.

Earlier surveys of Latinx scholars and other underrepresented groups highlight the importance of a sense of belonging when pursuing a specific career path. The chapter, 'Seeing Self,' describes our efforts to address a lack of belonging for minority scholars in STEM through the creation of the Center for Advancing Multicultural Perspectives on Science (CAMPOS). CAMPOS serves an important dual purpose. First, it aims to support a diverse community of STEM scholars by fostering belonging within the group; second, it showcases the individual successes of these scholars, thus broadening public perception of who belongs in STEM.

The chapter, 'Mentorship, Sponsorship, and Professional Networking,' discusses the importance of mentoring to faculty success and explains how to create comprehensive faculty mentoring programs. It is well known that women often cite deficits in mentoring as a top reason for leaving STEM careers (National Academy of Sciences, National Academy of Engineering and Institute of Medicine, 2007). Mentoring is important at multiple levels_-in-group mentoring to guide individuals along their career path, in-group mentoring of outgroup members to enable integration within the in-group, mentoring during undergraduate and graduate education (Bernard, 1965) and general mentoring to address issues unique to a subgroup.

The final chapter in this section, chapter, 'Work Life Integration in Academia,' discusses the conflict of identities that can occur when a scholar is both a professional and a parent. Work-life integration is often regarded as an elusive goal and may even become a career-choice barrier, especially for women academics. In this chapter, we review several work-life integration interventions at UC Davis, including dual career programs such as the Partner Opportunity Program and the Capital Resource Network (an initiative started under the UC Davis ADVANCE program); the expanded work-life program for academics at UC Davis as compared to those at other UC campuses; and additional family-friendly options, such as UC Davis's customized recruitment program. We discuss challenges experienced while conceptualizing and implementing these interventions, and we recommend best practices for improving work-life integration in academia and beyond. Instead of work-life balance programs that sustain a conflict of identities (worker versus mother, for example), we advocate a philosophy of work-life integration that views the two identities as distinct yet compatible parts of a whole.

\section{Part 5}

The final section of the book covers various challenges to establishing a truly inclusive climate for STEM scholars.

The chapter, 'Leading While Female,' shares the personal journey of our former Chancellor and the complexities involved in balancing loyalty to the existing organization with the desire to change it. It also discusses the problem of systemic gender 
bias in the institution and the impact this bias can have on female leaders seeking to create a more inclusive culture.

The chapter, 'Advice Not Taken,' discusses what we call "advice ignored." The goal of this chapter is to demonstrate how the efforts of organizations must be tailored to the local culture in order for institutional transformation to succeed. Commitments to inclusion must always be rooted within the community undergoing change and reflect an understanding of its priorities and goals. The chapter, 'Disrupting Complacent Systems,' discusses the concept of "complacent systems" - why cultural systems become complacent and what is necessary to disrupt them in order to effect change.

The final chapter, Chapter 15, summarizes the key lessons learned during the six years of implementing the ADVANCE program on our campus. We summarize the approaches that proved most successful and highlight the challenges that remain going forwards.

\section{Conclusion}

In writing this book, we have been motivated by the belief that knowledge is power. In the spirit of that belief, we offer our observations, reflections, and experiences of creating a more inclusive campus culture through institutional transformation. Our goal is to contribute to the important, ongoing dialogue on how to best ensure equity for all faculty in academia-and for all workers in the broader society.

Acknowledgements The authors thank our illustrators Meghan Crebbin-Crates (Fig. 5, Exclusion and Inclusion), Chastine Leora Madla (Figs. 3 and 4) and Mengmeng Luo (Fig. 5, Segregation and Integration). Their enthusiasm for this project and ability to bring concepts to life is greatly appreciated.

\section{References}

Bernard, J. (1965). The present situation in the academic world of women trained in engineering. In J. A. Mattfield \& C. V. Van Aken (Eds.), Women and the scientific professions. Cambridge: MIT Press.

California Ballot Pamphlet General Election: Proposition 209 Prohibition Against Discrimination or Preferential Treatment by State and Other Public Entities. (1996, November 5). Retrieved from http://vigarchive.sos.ca.gov/1996/general/pamphlet/209text.htm

Claiborne, W. (1997, April 9). Affirmative action ban is upheld. The Washington Post, p. A01. Retrieved from https://www.washingtonpost.com/wp-srv/politics/special/affirm/stories/aa0 40997.htm?noredirect=on

Connerly, W. (1997, April 9). Perspective on Prop. 209: Race preferences lose in court-again. Los Angeles Times. Retrieved from http://www.fullerton.edu/affirmativeaction/aanews/4-9-97 2.htm

Dhont, K., \& van Hiel, A. (2012). Intergroup contact buffers against the intergenerational transmission of authoritarianism and racial prejudice. Journal of Research in Personality, 46, 231-234. 
Douglass, J. A. (1997, February 28). A brief on events leading to SP1. University of California academic senate document submitted to the task force on governance panel 2 on shared governance. Revised 3.98. https://senate.universityofcalifornia.edu/_files/reports/sp1rev.pdf

Edelman, L. (1992). Legal ambiguity and symbolic structures: Organizational mediation of civil rights law. American Journal of Sociology, 97, 1531-1576.

F.3d 692, 66 USLW 3171, 97 Cal. Daily Op. Serv. 6966 (United States Court of Appeals March 3, 1997). Retrieved from https://law.resource.org/pub/us/case/reporter/F3/122/122.F3d.692.9715031.97-15030.html

Halim, M. D., Ruble, D. N., Tamis-LeMonda, C. S., Shrout, P. E., \& Amodio, D. M. (2017). Gender attitudes in early childhood: Behavioral consequences and cognitive antecedents. Child Development, 88, 882-899.

Kalev, A., Dobbin, F., \& Kelly, E. (2006). Best practices or best guesses? Accessing the efficacy of corporate affirmative action and diversity policies. American Sociological Review, 71, 589-617.

Kelly, E., \& Dobbin, F. (1998). How affirmative action became diversity management. American Behavioral Scientist, 41(7), 960-984.

Kendi, I. X. (2019). How to be an antiracist. Random House.

Kotter, J. P. (1995, March-April). Leading change: Why transformation efforts fail. Harvard Business Review, 59-67.

National Academy of Sciences, National Academy of Engineering \& Institute of Medicine. (2007). Beyond bias and barriers: Fulfilling the potential of women in academic science and engineering. Washington, DC: The National Academies Press. https://doi.org/10.17226/11741

Rossi, A.S. (1965). Barriers to the career choice of engineering medicine, or science among American women. In J. A. Mattfield \& C. V. Van Aken (Eds.), Women and the scientific professions. Cambridge: MIT Press.

Stewart, A. J., \& Valian, V. (2018). An inclusive academy: Achieving diversity and excellence. MIT Press.

University of California Academic Senate. (2003, February 23). University of California Academic Senate, Academic Council Agenda attachment 4.

Valian, V. (1998). Why so slow? The advancement of women. MIT Press.

West, M. S., Laky, G., Lokke, K., Paw, U., \& Ham, S. (2005). Unprecedented urgency: Gender discrimination in faculty hiring at the University of California. Report to the Institute for Women's Leadership, Rutgers University, under funding from the Ford Foundation project, "Re-affirming Action: Designs for Diversity in Higher Education."

Open Access This chapter is licensed under the terms of the Creative Commons Attribution 4.0 International License (http://creativecommons.org/licenses/by/4.0/), which permits use, sharing, adaptation, distribution and reproduction in any medium or format, as long as you give appropriate credit to the original author(s) and the source, provide a link to the Creative Commons license and indicate if changes were made.

The images or other third party material in this chapter are included in the chapter's Creative Commons license, unless indicated otherwise in a credit line to the material. If material is not included in the chapter's Creative Commons license and your intended use is not permitted by statutory regulation or exceeds the permitted use, you will need to obtain permission directly from the copyright holder.

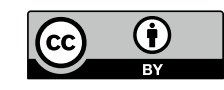

